\title{
Research on Catalytic Oxidation Pretreatment of Organic Pesticide Wastewater with High Concentration
}

\author{
Jing Jiang ${ }^{1, a}$ \\ ${ }^{1}$ Department of architectural and environmental Engineering, Chengdu Technological University, Chengdu 610000
}

\begin{abstract}
Pesticide wastewater has the characteristics of high organic pollutant, high concentration, deep color and high toxicity, which has become difficult to treat the organic wastewater with high concentration at home and abroad. This article uses three methods of US(ultrasonic), Fenton $\left(\mathrm{Fe}^{2+} \& \mathrm{H}_{2} \mathrm{O}_{2}\right)$ and combination of US\&Fenton were used in the comparative research on the treatment of organic pesticide wastewater with high concentration. Experimental conditions: time of $130 \mathrm{~min}$, ultrasonic power of $280 \mathrm{~W}$, frequency of $418 \mathrm{kHz}, \mathrm{pH}$ value of $3.5, \mathrm{H}_{2} \mathrm{O}_{2}$ concentration of $0.3 \mathrm{~mol} / 1$; dosing mode: two thirds was added at $0 \mathrm{~min}$, the rest one third was added at $65 \mathrm{~min}$. The results showed that the treatment effect of the combination of US\&Fenton was significantly better than that of independent US and independent Fenton; after the treatment on the organic pesticide wastewater with high concentration, the degradation rate of COD reached $85 \%$, the chromaticity degradation rate reached $99 \%$; the ratio of COD/BOD was about 1.4 , with better biodegradability, which has provided a good condition for the subsequent biochemical treatment. Solved the problem of pesticide wastewater was difficult and expensive to degradation.
\end{abstract}

\section{Introduction}

With the wide application of pesticide, pesticide wastewater discharged in the process of pesticide production has become a potential environmental hazard. This kind of industrial wastewater has become one of the pollutions which are the most seriously and the most difficultly treated in China. Advanced oxidation technology usually refers to the treatment technology which oxidizes and degrades organic pollutants by producing high-reactivity hydroxyl radicals $(\mathrm{HO})$ under ambient temperature and pressure, including the photocatalytic oxidation, $\mathrm{O}_{3}$ oxidation, Fenton reagent oxidation as well as the combinations of oxidation technology. The application of advanced oxidation technology to treat landfill leachate, pesticide wastewater and dye wastewater has been reported in the literature [1-5]. However, due to the characteristics of pesticide wastewater, the application of advanced oxidation technology is not yet common in practice.

The composition of pesticide wastewater is complex, containing a large number of toxic and harmful substances, resulting in its poor biodegradability; the use of traditional biochemical treatment method is generally difficult to get good treatment results, so it is needed to strengthen the pretreatment of wastewater $[6$, 7].

The combination of Fenton method and ultrasonic method was used to pre-treat the organic pesticide wastewater with high concentration, and the effect of the process conditions on US\&Fenton treatment system was discussed.

\section{Experiment}

\subsection{Experimental materials}

Wastewater used in the experiments is from a chemical plant in Chengdu, the wastewater is reddish brown, with strong pungent odor, and poor biodegradability. According to the report of wastewater detection, the water mainly contains dimethyl phthalate, tributyl phosphate, etc.

Experiment reagents: $\mathrm{FeSO}_{4} \cdot 7 \mathrm{H}_{2} \mathrm{O}$ ( analytical reagent $\mathrm{AR}$ ) , $30 \% \mathrm{H}_{2} \mathrm{O}_{2}$ (analytical reagent $\mathrm{AR}$ ), $\mathrm{K}_{2} \mathrm{Cr}_{2} \mathrm{O}_{7}$ (analytical reagent AR)

Experimental apparatus: Visible spectrophotometer $721 \mathrm{G}$ (Shanghai Precision Scientific Instrument Co., Ltd.), JY92 - II ultrasonic instrument (Ningbo scientz Biotechnology Co., Ltd.), PHS-3B digital precision $\mathrm{pH}$ meter (Shanghai Leici Instrument Factory).

\subsection{Experimental methods}

Put wastewater in the reactor, add a certain amount of ferrous sulfate and hydrogen peroxide, turn on the ultrasound instrument, and add $\mathrm{H}_{2} \mathrm{O}_{2}$ according to a certain way under the condition of aeration rate of 150 $\mathrm{L} / \mathrm{h}$. After a period of time of reaction, adjust the $\mathrm{pH}$

\footnotetext{
${ }^{a}$ Corresponding author: 25859260@qq.com
} 
value to 10 , and then wait $1 \mathrm{~h}$, finally take the supernatant for the index measurement.

The initial concentration of water sample COD was $2253 \mathrm{mg} / \mathrm{L}$, the ultrasonic frequency was $418 \mathrm{kHz}$, the power was $280 \mathrm{~W}$, the $\mathrm{pH}$ value was 3.5 , the concentration of $\mathrm{Fe}^{2+}$ was $25 \mathrm{mmol} / \mathrm{L}$, the concentration of $\mathrm{H}_{2} \mathrm{O}_{2}$ was $0.3 \mathrm{~mol} / \mathrm{L}$, and the three kinds of treatment methods of independent Fenton, independent US and combination of US\&Fenton were used to treat wastewater for $130 \mathrm{~min}$.

\subsection{Analysis method}

Potassium dichromate method was used to determine wastewater $\mathrm{COD}[8] ; \mathrm{Fe}^{2+}$ concentration and total iron concentration were measured according to HJ/T345-2007 “Water Quality Determination of the Iron Phenanthroline Spectrophotometric Method" [9].

\section{Results and Discussion}

\subsection{Degradation of COD with different methods and color contrast}

It can be known from Fig 1 that the degradation effect of independent US on water sample COD was not obvious, it was only $15 \%$, the maximum value was reached at 90min. The degradation effect of independent Fenton on water sample COD was $65 \%$, the maximum value was reached at about $90 \mathrm{~min}$. The degradation effect of combination of US\&Fenton on water sample COD was up to $85 \%$, which was more than the degradation sum of independent US and independent Fenton, and it reached the maximum value at $130 \mathrm{~min}$, and tended to be stable, proving US and Fenton have synergistic effect, and its degradation effect on water sample COD was obvious. The COD value of water sample reduced from 2253 to 338 , the ratio of $\mathrm{COD} / \mathrm{BOD}$ was about 1.4 , the biodegradability was better, which have achieved the pretreatment effect of pesticide wastewaters with high concentration.

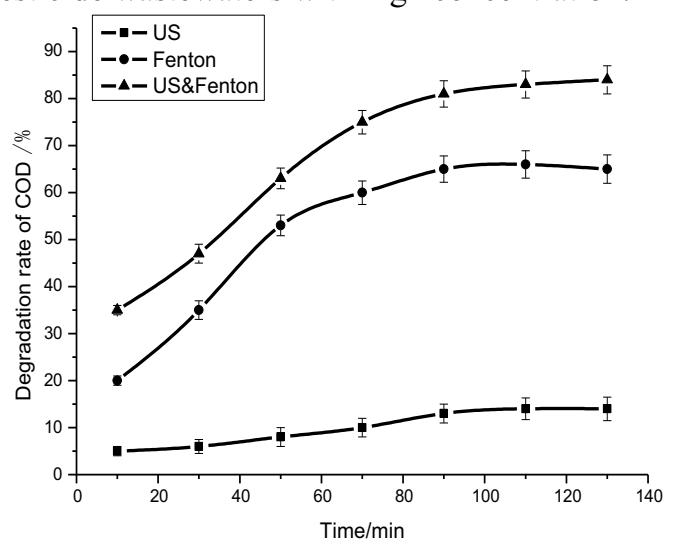

Figure 1. COD degradation with different methods

Figure 2 shows the degradation rate contrast of 3 methods for the water samples in the experiments. The degradation rate of US on experimental water sample was $30 \%$, and the highest value was reached at $90 \mathrm{~min}$.
The degradation rate of Fenten was $74 \%$, and the highest value was reached at $90 \mathrm{~min}$. The degradation rate of US\&Fenten on the chromaticity in experimental water sample reached $99 \%$, the highest value was reached in $110 \mathrm{~min}$; the reaction process was more durable, the treatment effect was significantly higher than those of the US and Fenten. The pretreatment effect of the combination of US\&Fenten on organic pesticide wastewater with high concentration was obvious, achieved the goal of the wastewater pretreatment, which has provided favorable conditions for follow-up biochemical treatment.

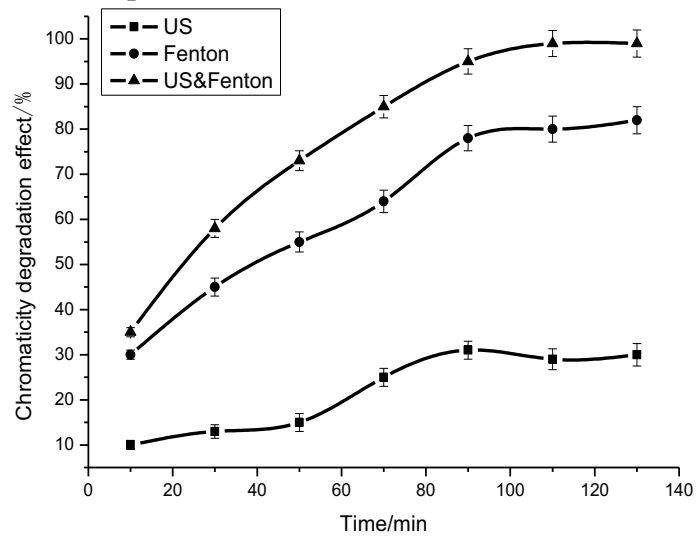

Figure 2. Chromaticity degradation effect with 3 different methods

\subsection{Effect of $\mathrm{pH}$ value on degradation rate}

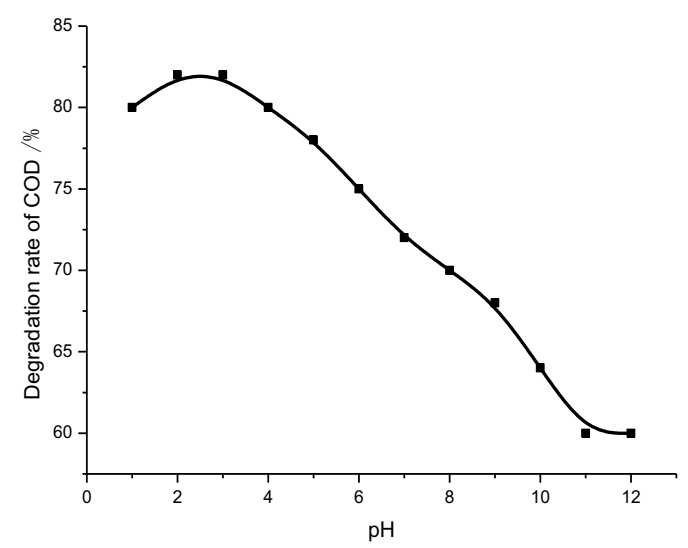

Figure 3. Effect of $\mathrm{pH}$ value on $\mathrm{COD}$ degradation rate

With the combination treatment method of US\&Fenten, it can be seen from Figure 3 that the experimental conditions were as follows: the initial concentration of experimental water samples COD was $2253 \mathrm{mg} / \mathrm{L}$, ultrasonic frequency was $418 \mathrm{kHZ}$, the power was $280 \mathrm{~W}$, the concentration of $\mathrm{Fe}^{2+}$ was 25 $\mathrm{mmol} / \mathrm{L}$, the concentration of $\mathrm{H}_{2} \mathrm{O}_{2}$ was $0.3 \mathrm{~mol} / \mathrm{L}$. it can be seen from Fig 4 that when the $\mathrm{pH}$ value is $2 \sim 5$, the degradation efficiency of COD was higher; when the $\mathrm{pH}$ value was 3 , the degradation rate of COD had its peak value, and the degradation efficiency decreased with the increase of $\mathrm{pH}$ value. Therefore, it is concluded that the optimum condition is the $\mathrm{pH}$ value of 3.5 . This is because when the $\mathrm{pH}$ value is less than 3, $\left[\mathrm{Fe}(\mathrm{II})\left(\mathrm{H}_{2} \mathrm{O}\right)_{6}\right]^{2+}$ will be produced in the system, the reaction rate of the compound with $\mathrm{H}_{2} \mathrm{O}_{2}$ is lower than 
that of $\left.\mathrm{Fe}(\mathrm{II})(\mathrm{OH})\left(\mathrm{H}_{2} \mathrm{O}\right)_{5}\right]^{+}$, thus, reducing the production of $\mathrm{OH}$, affecting the effect of catalytic oxidation reaction [10]. And when the $\mathrm{pH}$ value is much higher, it not only inhibits the production of $\mathrm{OH}$, but also makes $\mathrm{Fe}^{2+}$ and $\mathrm{Fe}^{3+}$ in the solution subside in the form of hydroxide precipitation and lose catalytic ability; at the same time, the higher $\mathrm{pH}$ value will make the $\mathrm{H}_{2} \mathrm{O}_{2}$ produce invalid decomposition, reducing the utilization rate of $\mathrm{H}_{2} \mathrm{O}_{2}$ [11].

\subsection{Effect of ultrasonic parameters on the degradation rate}

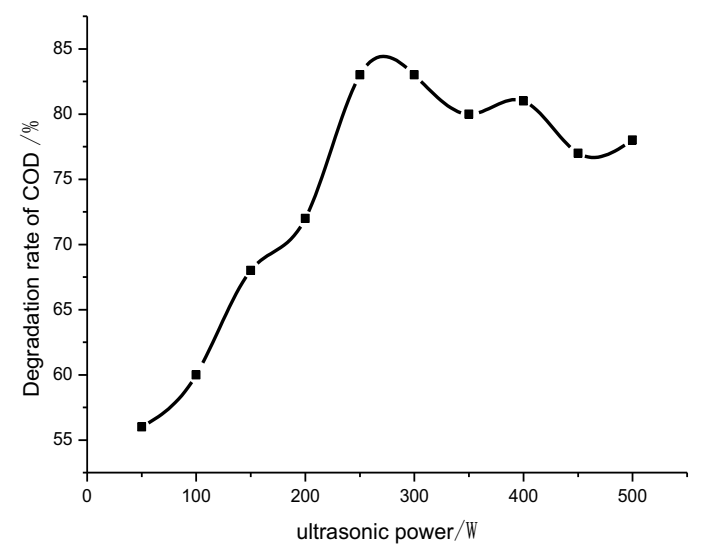

Figure 4. Effect of ultrasonic power on the COD degradation rate

With the combination treatment method of US\&Fenten, the experimental conditions were as follows: the initial concentration of experimental water samples COD was $2253 \mathrm{mg} / \mathrm{L}$, the $\mathrm{pH}$ value was 3.5, the concentration of $\mathrm{Fe}^{2+}$ was $25 \mathrm{mmol} / \mathrm{L}$, the concentration of $\mathrm{H}_{2} \mathrm{O}_{2}$ was $0.3 \mathrm{~mol} / \mathrm{L}$. it can be seen from Figure 4 that degradation efficiency of COD increased with the increase of the power of ultrasonic power, peaked in $200 \sim 300 \mathrm{w}$; when the power is greater than 300 , the degradation rate of COD decreased. Generally speaking, when the ultrasonic frequency is constant, the degradation effect should increase with the increase of power, the phenomenon in the experiment is speculated that too great power will result in the barrier effect caused by cavitation bubbles in ultrasonic larger negative phase, resulting in instable energy and attenuation, thereby reducing the utilization rate of ultrasonic energy [12, 13]. As a result, too great ultrasonic power may cause energy waste, from the perspectives of economy and treatment effect, it is determined that the best ultrasonic power is $280 \mathrm{~W}$.

\subsection{Effect of $\mathrm{H}_{2} \mathrm{O}_{2}$ dosage on degradation rate}

With the combination treatment method of US\&Fenten, the experimental conditions were as follows: the initial concentration of experimental water samples COD was $2253 \mathrm{mg} / \mathrm{L}$, the ultrasonic power was $280 \mathrm{~W}$, the $\mathrm{pH}$ value was 3.5 , the concentration of $\mathrm{Fe}^{2+}$ was $25 \mathrm{mmol} / \mathrm{L} . \mathrm{H}_{2} \mathrm{O}_{2}$ with different concentrations was added; the organic pesticide wastewater with high concentration was treated with the combination method of US\&Fenton for catalytic oxidation degradation for $130 \mathrm{~min}$, the result is shown in Figure 5.

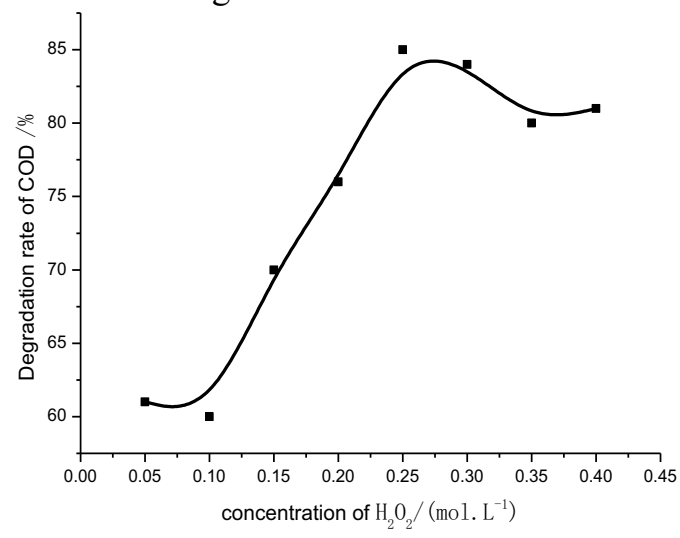

Figure 5. Effect of $\mathrm{H}_{2} \mathrm{O}_{2}$ concentration on COD degradation rate

It can be seen from the Figure, when the concentration of $\mathrm{H}_{2} \mathrm{O}_{2}$ in the solution was less than 0.25 $\mathrm{mol} / \mathrm{L}$, it increased with the concentration of $\mathrm{H}_{2} \mathrm{O}_{2}$, the degradation rate of COD in experimental sample water was increased. When the concentration of $\mathrm{H}_{2} \mathrm{O}_{2}$ in the solution increased to $0.25 \sim 0.3 \mathrm{~mol} / \mathrm{L}$, the degradation rate reached its peak; afterwards, the degradation rate of COD in experimental sample water decreased with the increase in the concentration of $\mathrm{H}_{2} \mathrm{O}_{2}$. Therefore, it is established that the best experimental concentration condition of $\mathrm{H}_{2} \mathrm{O}_{2}$ is between $0.25 \sim 0.3 \mathrm{~mol} / \mathrm{L}$.

\section{Conclusions}

Under the experimental conditions of $418 \mathrm{kHZ}$ ultrasonic frequency, the $280 \mathrm{~W}$ power, $3.5 \mathrm{pH}$ value, $25 \mathrm{mmol} / \mathrm{L}$ concentration of $\mathrm{Fe}^{2+}, \quad 0.3 \mathrm{~mol} / \mathrm{L}$ concentration of $\mathrm{H}_{2} \mathrm{O}_{2}$, three methods were used to treat organic pesticide wastewater with high concentration for $130 \mathrm{~min}$; the results proved that the effect of combination treatment method of US\&Fenton was the best, COD degradation rate reached $85 \%$, chromaticity degradation rate reached $99 \%$, the ratio of COD/BOD was about 1.4 , with better biodegradability, which has provided a good condition for the subsequent biochemical treatment.

\section{References}

1. Zhang Yongpeng, Zhou Junying, et al. Research Progress of Application of Several Advanced Oxidation Technology in Pesticide Wastewater Treatment [J] Journal of Pesticide Science, 2007, 9(2):103-109.

2. Zhang Zhisheng, Li Guangming et al. Research Progress of Advanced Oxidation Technology for Treatment of Landfill Leachate [ J ] Sichuan Environment, 2005, 24(5):72-78.

3. Li Wenshu, Li Yongmei, et al. Application of Advanced Oxidation Technology in the Treatment 
of Persistent Organic Pollutants [ J Industrial Water Treatment, 2004, 24(11):9-12.

4. Zhang Yi, Hu Bing, et al. Research Progress on Advanced Oxidation Technology for Degradation of Organic Ohosphorus Pesticides in Water $[\mathrm{J}]$ Environmental Pollution \& Control , 2006, 28(5):361-3 64.

5. Liu Yan, Sun Dezhi, et al. Research Progress on Advanced Oxidation Technology for Treatment of Dye Wastewater J] Industrial Water Treatment, 2006, 26(6):1-5.

6. Ge Xiangfeng, Xu Mingfang, et al. Analysis of Influencing factors of the Photocatalytic Degradation of Trichlorfon Pesticide Wastewater [J] Ecological Science, 2004, 23(2):1 24-127.

7. Wu Qimo, Wu Jianzhong, et al. Treatment of Pesticide Wastewater by Oxidation Process [ $\mathrm{J}]$ Environmental Engineering, 2005, 23(5):88-90.

8. Editorial board of National Environmental Protection Bureau "Detection and Analysis Methods of Water and Wastewater" [M] Fourth Edition, Beijing: China Environmental Science Press, 2002: 210-211,
9. China's Environmental Monitoring Station. HJ/T345-2007 “Water Quality Determination of the Iron Phenanthroline Spectrophotometric Method"' [S] Beijing: China environmental science press, 2007.

10. He Dewen, Qin Yan et al. Experimental Study on Treatment of Ultrasonic Oxidation for Printing Ink Wastewater [J] Journal of Central South University, 2009, 40(6):1483-1487.

11. Chen Chuanhao, Xie Bo, et al. Mechanism of the Influence Factors in Fenton Reagents for the Treatment of Wastewater [J] Environmental Science, 2000, 21(3):93-96.

12. Yoshio N , Michiyo N , Hiroshi O.Sonochemicaldegradation of chlorophernols in water[J].Ultrason Sonochem, 2000, 7(3): 115-120.

13. Su Chunyan, Guan Jie, et al. Study on Catalytic Oxidation Degradation of Nitrobenzene in Pharmaceutical Wastewater [J]. Journal of Changchun University of Technology, 2008, 29(5): 575-578. 